\title{
A Global Investigation of Granger Causality between Information Infrastructure Investment and Service-Sector Growth
}

\author{
Pratim Datta
}

Department of Information Systems, Washington State University, Pullman, Washington, USA

\author{
Victor W. Mbarika \\ Department of Management, Marketing, and E-Business, Southern University \\ and A\&M College, Baton Rouge, Louisiana, USA
}

Over the past two decades, both developed and developing countries have been investing a significant portion of their resources in the creation of an information infrastructure. However, speculation abounds regarding the efficacy of information infrastructure investments, especially when the opportunity cost for investing in information technology (IT) is measurably high among developing nations. This longitudinal study introduces and explores infrastructure development and service-sector growth as key metrics for IT investment success. It also traces the notional evidence of IT infrastructure development as mediating the causal relationship between information infrastructure investments and service-sector growth. Using data from low-income, middle-income, and highincome countries, the mediating and lagged impact of information infrastructure on service-sector growth reveals that information infrastructure development does play a significant role as a mediator. It points out that information infrastructure investments can be a misleading causal antecedent if countries fail to develop their infrastructure. It also provides evidence of a recursive relationship between infrastructure development and service-sector growth. An exploratory time-series analysis across different country categories suggests that information infrastructures must be properly developed to reconcile the paradox. In addition, exploratory tests reveal a distinct divergence between infrastructure investments and infrastructure development among different country tiers.

Keywords Granger causality, information infrastructure development, information infrastructure investment, national growth, service-sector growth

Received 21 March 2005; accepted 23 December 2005.

Address correspondence to Pratim Datta, Department of Information Systems, Washington State University, Todd Hall 437F, P.O. Box 644743, Pullman, WA 99164, USA. E-mail: pdatta@wsu.edu
Expectations of economic gains in the so-called information age have prompted both developed and developing countries to invest a significant portion of their resources in improving their information infrastructure ${ }^{1}$ (King et al., 1994). It has long been argued that investing in an information infrastructure is a prerequisite for national development (Brynjolfsson, 1993; Dewan \& Kraemer, 1998), yet the underlying dynamics of this relationship remain "a major, largely unreported, understudied IT [information technology] story" (Cash et al., 1988, p. 216). As a result, developing countries have tried to mimic advances in the developed world by laying out significant resources for information infrastructure investments (IIINV): ${ }^{2}$ spending trillions to acquire emerging information technologies.

An information infrastructure has long been believed to be an "equalizer": allowing nations to access information that was once not available, thus bridging the gap between developed and less developed countries. It has also often been correlated to the reduction of entry barriers for service-sector enterprises, leading to significant growth in services ranging from banking and finance to health care and application development. Service-sector growth, in turn, is seen as triggering subsequent investments in information infrastructure, leading to further economic activity. For example, in a study of Asian countries, Chakraborty and Nandi (2003) found that information infrastructure and economic development were co-integrated in the long run, offering bidirectional causality. Yet, for the most part, these statements have turned out to be nothing more than a series of optimistic conjectures, which have escaped scrutiny by scholars. Unfortunately, this has let information technology (IT) vendors use such claims to sell their wares. 
To interrogate such claims, we question whether arguments linking IIINV to economic development are globally true or mere instantiations for developed economies. Correspondingly, we question: Can IIINV truly lead to service-sector growth (SSG) and does SSG trigger future information infrastructure growth? What differentiates the degree of SSG resulting from investing in an information infrastructure between developed and less developed nations? Is there a missing piece of the puzzle that researchers have failed to examine? In this article, we specifically examine: What is the relationship between information infrastructure investment and service-sector growth? What is the direction and causality of this relationship, if any? And does this relationship vary across countries?

Capital and labor prerequisites for manufacturing far outweigh that of the service sector because service industries rely more on knowledge capital and have lower entry barriers (startup costs) (Adedji, 1986; Mbarika et al., 2002). For example, the low capital requirements and easy availability of knowledge workers have propelled the growth of the transcribing industry in India. There are many other such examples of visible success and notable growth in the service industries in a number of developing countries. While in developed nations the positive link between IIINV and growth in the service sector is taken for granted, empirical research has revealed contradictory findings regarding growth gains from IIINV (Dowling et al., 1994; Mbarika et al., 2001)—-largely blamed on the mismeasurement of output. ${ }^{3}$

Furthermore, the assumption that IIINV is a sufficient cause for future SSG has escaped scrutiny by scholars. In this article, we argue that IIINV does not prompt SSG; however, the widespread adoption and use of the information infrastructure or information infrastructure development (IID) do (Datta, 2002). Some countries invest heavily in securing an information infrastructure but fail to extend the technology to the population beyond a few urban clusters and bureaucratic institutions. In contrast, other countries are relatively more effective in disseminating information technologies to the greater population, thereby creating conditions for increased adoption and use. Succinctly, while IIINV focuses on how much is spent on information infrastructure, IID stresses on how effectively it is spent, assuming that technology is effective only when openly adopted and used. Research has long implicated the need for robust IID as a logical precursor to productive gains (Sirimanne, 1996), but little has been done either conceptually or empirically to understand the relationship between IIINV, IID, and SSG, especially at a macroeconomic level. According to Soh and Markus (1995), development of a technological infrastructure, rather than mere technological investments, is the key for achieving future economic growth. Regardless of the intensity of IIINV, without a developed infrastructure, investments do not pay off in terms of economic growth. Yet researchers have tended to see IIINV as a necessary and sufficient precondition. There are notable exceptions (Datta, 2002; Sirimanne, 1996), although both few and far apart, who have considered both IIINV and infrastructure development as precursors to economic growth. Even so, data collection has been haphazard and unsystematic, lacking evidence of comparative studies conducted across nations to dispel variances in IIINV, IID, and SSG.

Finally, another interesting yet less researched issue is the recursive relationship between infrastructure development and service-sector growth. The recursive relationship becomes evident upon observing the development of IT hubs in places like Bangalore, India; Tel Aviv, Israel; Palo Alto, CA; and Derry, Ireland. These areas share a common thread that has propelled their growth within the past decade - their service sector. IT has enabled the sprouting of a new genre of economically viable services, from application outsourcing to software development. The growth and acceptance of such services allow for a greater use of information infrastructure services. As usage increases, spillover benefits grow, leading to greater IID (Dutta, 2001). Yet, with the exception of a handful of researchers (Dutta, 2001), rarely have there been inquiries on the recursive causalities between infrastructure development and economic growth.

In what follows, we empirically investigate the relationships between IIINV, IID, and SSG. We use a process-theoretic perspective to develop a process framework and hypothesize relationships between our variables of interest. We then empirically test our hypotheses across three different global economic categories-highincome countries, medium-income countries, and lowincome countries - to validate the strength and direction of our proposed process framework across these different country tiers: to understand distinct global differences. We close with a discussion of our findings.

\section{THEORETICAL DEVELOPMENT}

\section{Information Infrastructure Investment}

As evident in multiple streams of information systems (IS) research, IIINV remains a potential antecedent to understanding economic growth. Information infrastructure has generally been thought only in terms of easily measurable, objective IT investments (Dutta, 2001). This attraction toward ease of operationalization and an overemphasis on IINV has limited our concept of infrastructure. We need to be mindful of the fact that investment is an act of disbursement: implicating magnitude rather than direction of economic capital. In an extensive longitudinal study performed by Wang (1999) concerning the impact of IIINVs on national SSG in Taiwan, the author posited that investments do not matter; what matters is the need for 
developing a robust information infrastructure as a precursor to economic gains.

Nevertheless, the use of IIINV as an input variable is widespread in mainstream IS literature (e.g., Dutta, 2001). Using the well-established Granger test for causality, Dutta (2001) argues persuasively that there is a recursive causal relationship between IIINV and SSG. His findings provide additional insights into the complex relationship between information infrastructure and SSG. This study, an attempt to capture this complexity, contends that IIINV is a necessary but not a sufficient prerequisite for SSG. Instead, information infrastructure development is seen to be the essential link between investments and economic growth. Still, multiple streams of research (Mbarika et al., 2001; Chifwepa, 1998; Roach, 1991) in organizational and macro-level economic development have used IIINV as a single and sufficient input in the economic development and growth equations. Given that productivity leads to and sustains economic growth, mainly through the rapid expansion of the service-sector economy, we extend the relationship to propose the following hypothesis:

$\mathrm{H}_{1}$ : Information infrastructure investment in a particular period will positively impact service-sector growth in a later period.

\section{Information Infrastructure Development}

In contrast to IIINV as a function of capital outlays, infrastructure development is a function of effective dissemination, adoption, and use of the information infrastructure. For example, there are cases in Sub-Saharan Africa where governments invested considerable sums toward buying information infrastructure, with little understanding of its proper use. Even those governments that did know how to use the technology allowed their population very little access to the technology. As a result, the acquired information infrastructure remained seriously underdeveloped, falling short of any productive potential. Information infrastructure development, therefore, as an intervening condition, makes IIINV a necessary but not a sufficient precondition for understanding economic productivity and growth. As Weill (1992) and Soh and Markus (1995) suggest, the inclusion of IID offers a better understanding of service-sector growth, compared to the sole use of IIINV.

Soh and Markus (1995) show that a given amount of infrastructure investment does not necessarily signify infrastructure development in organizations; they note that organizations with similar IIINV exhibited significant variances in their IID. This suggests that the same is likely to be true at the macroeconomic level. Because investments do not guarantee a specific degree of infrastructure development, the disparity can have significant ramifications on national economies, even under circumstances of similar infrastructure investments (Soubbotina \& Sheram, 2000).

Ethiopia serves as a good example. In the past 5 years, Ethiopia has spent a considerable fortune in developing a digital data network (DDN) called Ethio-Stream (Light, 1999; United Nations Development Program, 2001). Substantial investments were incurred for acquiring technologies such as frame relays, ISDNs, dedicated Internet access, and leased circuit lines, among many others. The technology remained limited to government officials, bureaucrats, and a handful of urban elite. As a result, Ethiopia could neither support nor maintain its information infrastructure because of a lack of user base. In other words, Ethiopia's preoccupation on investing in hardware and networks rather than widespread dissemination and usage by all sections of the population led to a severe underutilization of the country's IIINV.

IID brings together a rich set of assets, encompassing two separate but interacting components: (1) the technical component (e.g., telephone lines) that provides access, and (2) the users of the technical component (e.g., the telephone subscribers/users). IID involves both current and evolving technologies and its users and consists of the following IID components: (1) conventional analog land-based telephone and telex networks (McLoughlin, 2000); (2) satellite and wireless networks (McLoughlin, 2000); (3) broadband landbased networks (Lee, 1993); (4) computing hardware (McLoughlin, 2000; Wang, 1999); (5) computing software and applications (Beltz, 1997); (6) content management (databases) (McLoughlin, 2000); and (7) human capital (Lamberton, 1996), in terms of the human resources supporting the information infrastructure. Altogether, IID provides an installed base for the use of the information infrastructure. Because the value of IID lies in its use, consumers and (internal) users of the information infrastructure become ever-important phenomena.

Although investments in information infrastructure have yielded limited positive impacts in some developing countries (Mbarika et al., 2001, 2003), we posit that the reason has been that the investments have failed to contribute toward infrastructure development in terms of greater access and availability along with a critical mass of users/adopters. Apostopoulos and Pramataris (1997) find that IIINV has a considerable impact on IID as a precursor to further growth. A developed information infrastructure provides an asset base (technical and human) that can be used toward increased opportunities for the service sector, leading to potential growth conditions (Soubbotina \& Sheram, 2000; Talero, 1997). This allows us to present the following hypotheses:

$\mathrm{H}_{2 \mathrm{a}}$ : Information infrastructure investment in a particular period will positively impact information infrastructure development. 
$\mathrm{H}_{2 b}$ : Information infrastructure development in a particular period will positively impact service-sector growth in a later period.

\section{Service-Sector Growth}

Previous studies indicate the economic benefits derived from developing a robust information infrastructure. Antonelli (1993) asserts that positive externalities derived from robust information infrastructure yield economic advantages that far outweigh actual marginal monetary revenues. Most of this economic advantage stems from potential spillover benefits accrued from the growth of the service sector (Baily et al., 1994). In reporting their findings, Baily et al. (1994) state that $85 \%$ of IIINV could be attributed to the U.S. service sector, which accounted for $74 \%$ of the country's gross domestic product (GDP). Similar cases abound across the globe, postulating a dramatic shift toward a service economy in the information age. Consider Ireland as an example. After its independence in 1926, more than half of its population was engaged in the extractive industries of mining and forestry. Lately the economy has seen a rapid transformation, as the service sector now contributes toward the employment of over half the population. Similar trends are evident in other countries, such as India, Israel, the Philippines, China, and Lithuania, among others. Clearly, then, in the area of economic development, the service sector is gaining importance for the national economies. In most industries, there is increasing evidence of service-level commitments, agreements, and contracts with companies providing services rather than products. For example, IBM's divesting of its ThinkPad line to Lenovo in China and refocusing itself on consulting services is a prime example of the changing landscape.

Research conducted by the National Science Foundation (Mohr, 1982) on the U.S. economy attributes information infrastructures "as being a key reason for the structural shift from manufacturing to services... driven entirely by 'knowledge' industries" (Mohr, 1982). Among others, these "knowledge" industries include service-sector firms such as banking, insurance, air transport, telecommunications, software, technical consulting, and consulting services (Center for European Economic Research, 2002; Mohr, 1982). A comprehensive study of German firms by the Center for European Economic Research (Center for European Economic Research, 2002) noted that servicesector firms exhibited the greatest propensity for innovation, enhancing areas of information infrastructure such as mobile telephone use and Internet access, led by developments in telecommunications and electronic data processing (EDP). The positive impact of service industries on the information infrastructure can be seen in the increasing growth in the use of information-related products and services as well as a preponderance of trained informationsupport personnel. Although the reports are comprehensive in nature, they are still exploratory findings, motivating the search for confirmatory analyses of any causal recursive relationships between information infrastructure and economic growth in terms of service-sector contributions, taking into consideration lagged effects.

The preceding illustrations demonstrate the increasing importance of the service sector in the information age. In reporting sectoral impact, Soubbotina and Sherman (2000) highlighted that service-sector contributions were positively related to GDP and were pronounced across a variety of economies. As a country undergoes economic progress, the service sector supplants other sectors to become the leading contributor toward the economy, as in the aforesaid case of Ireland (Curtis \& Murthy, 1996). As Madden and Savage (1998, p. 174) note, the "service sector's contribution to growth is primarily attributable to positive externalities. These arise from increased service sector output based on the sectoral specialization and inter-sectoral trade, and a broader reorganization... that accompanies service sector output growth."

Sikes (1987, p. 330) stresses that information-intensive activities that promote national growth are brought forth by the "salient market force of services in virtually all sectors of national economies." Subsequently, information infrastructure provides leverage through service-sector innovations that promote entrepreneurship and growth (Dowling et al., 1994). Likewise, Roach (1991), in studying the impact of developed information infrastructure on service industries in the United States, found that the service sector born out of an information infrastructure has been the heart of the "stunning productivity" of the United States. Based on the strong evidence and claims from previous research on information infrastructure and the service industry, we contend that the economic impact of information infrastructure is better understood in terms of the growth of the service sector, given that infrastructure development is in place.

Developing a robust information infrastructure is therefore considered pivotal for productivity, leading to economic development (Madden \& Savage, 1998) via the growth of the service sector. However, deriving benefits from IIINVs is a two-stage process. First, investments in information infrastructure impact the development of the information infrastructure (Apostopoulos \& Pramataris, 1997; Mbarika et al., 2002). Once IID takes place, it is said to impact service-sector growth (SSG) (Weill, 1992). While investments may be the same, variation in IID could stem from country-specific attributes. Because IID is tied to and is proposed to be a precursor to SSG, levels of IID would lead to different degrees of SSG. In tying IIINV, IID, and SSG within the same equation, we propose that 
IID mediates the relationship between IIINV and SSG, leading to hypothesis $\mathrm{H}_{3}$ :

\section{$\mathrm{H}_{3}$ : Information infrastructure development will mediate the causal relationship between information infrastructure in- vestments and service-sector growth.}

Recursively, the positive impact of service industries on the information infrastructure can be traced by increasing growth in the use of information-related products and services, as well as demand for users of information related services. Consider the example of automated teller machines (ATMs) in financial services. The development and use of ATMs lead to rapid service-level growth, promoting adoption across a growing user base of ATM users. Similarly, with increasing IID, positive adoption and spillover effects of technology can promote IIINV and nurture steady IID growth. While anecdotal evidence abounds on the recursive relationship, it is still sketchy, thus, motivating the search for confirmatory analyses of any causal recursive relationships between IID and SSG, taking into consideration lagged effects. While evidence of inherent time lags between IIINV and economic growth has been well documented by researchers (Brynjolfsson, 1993), there has been a paucity of empirical corroboration focused on bringing together the time lagged and recursive relationship between IID and SSG. Hence, we propose the following hypothesis.

\footnotetext{
$\mathrm{H}_{4 \mathrm{a}}$ : Information infrastructure development in a particular period will positively and recursively impact information infrastructure investment in a later period.

$\mathrm{H}_{4 \mathrm{~b}}$ : Service-sector growth in a particular period will positively and recursively impact information infrastructure development in a later period.

$\mathrm{H}_{4 \mathrm{c}}$ : Service-sector growth in a particular period will positively and recursively impact information infrastructure investment in a later period.
}

The proposed hypotheses integrate the constructs of IIINV, IID, and SSG within a recursive and lagged relationship. In the process of integrating the constructs, we borrow and augment preceding research though elaboration and empirical validation. We include the essence of temporal lags and methodology, while bringing to the fore the importance of information infrastructure development as a mediating variable and looking at service-sector growth as a veritable consequence of an information age. The proposed model is shown in Figure 1.

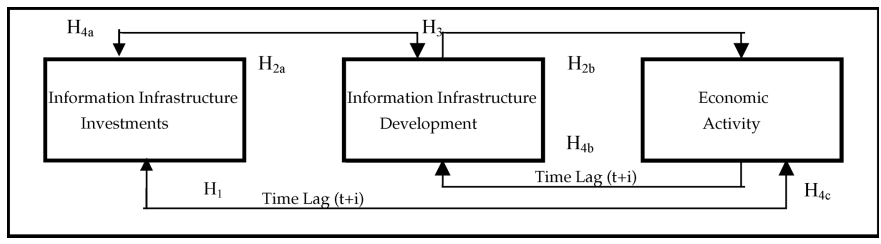

FIG. 1. Proposed model and hypotheses.

\section{METHODOLOGY}

\section{Data Collection and Analysis}

We collected time-series data for 90 countries, equally ordered into three groups, based on income. The countries were grouped based on the comprehensive list developed by the World Bank and sorted by income. From the comprehensive list of 218 countries, we chose three tiers, each consisting of 30 countries, randomly sampled. The final set of countries $(n=90)$ included the top 30 high-income countries $\left(n_{1}\right)$, the median 30 middle-income countries $\left(n_{2}\right)$, and the bottom 30 lowincome countries $\left(n_{3}\right)$, totaling 90 countries in our data set. Unidirectional causality and the mediation effects of IID were tested on each country group and the total set.

The motivation for forming the three groups, a highincome tier, a middle-income tier, and a low-income country tier, was as follows: Each of these categories represents distinct properties in terms of institutional policies, economy, and culture (SAS Institute, 2001; Strassman, 1997; Soh \& Markus, 1995). Given that each of these tiers manifests chronic differences, it would be interesting to observe whether and how IID and SSG accruals vary across country categories, whether IID indeed mediates the relationship, and whether there is a recursive relationship between IID and SSG. Additionally, the selection provides a comparative plane for assessing not only the existence of a relationship, but also its magnitude. Our country selection is set to augment previous studies that have examined the causality between infrastructure and growth between developing and industrialized countries by considering three tiers of countries in terms of their income. Along with increased granularity, such a sample would also be diverse and interesting, lending insight into countries across varying states of income. However, as with any choice of samples, the limitations of this set will be subsequently addressed.

Secondary time-series data were collected on countries for the purposes of a comparative study. Extending Dutta's (2001) time-series data for 15 developing countries and 15 industrialized countries, we try to look at a comparative set of 30 low-income countries, 30 middle-income countries, and 30 high-income countries $\left(n=90 ; n_{i}=30\right.$, where $i=$ country group $1,2,3$ ). Because we use the construct of "information infrastructure development" to comprise a variety of IT-related components that have been newly acquired, our longitudinal data set spans from 1996-2000 and thus involves both legacy and emergent information infrastructure technologies.

Service-sector growth at a national level was measured using service-sector contribution toward GDP. The growth of the service-sector as a consequence of information infrastructure has been widely reported in previous research (Mohr, 1982; Center for European Economic 
Research, 2002; Curtis \& Murthy, 1996). For example, in a longitudinal study of Organization for Economic Cooperation and Development (OECD) countries spanning from 1964 to 1992, Curtis and Murthy (1996) use service-sector contribution as a legitimate operational variable, especially while discussing the role of informationrelated industries as potential engines of GDP. The data on service-sector contribution were obtained from tables published by OECD and the Economist Intelligence Unit (EIU) database. The list of low-income, middle-income, and high-income countries was obtained from the World Bank, while data concerning service-sector contribution to GDP were gathered from both the United Nations Conference on Trade and Development (UNCTAD) and the International Telecommunications Union (ITU). National-level IIINV data was obtained from the ITU database.

Similarly, we use both technical and human measures for the construct of IID. The measures include the total number of technology access points (standardized by technology per 100) and users for each of the information infrastructure components, that is, telephones, telex lines, cellular phones, ISDN lines, personal computers, and trained telecommunications personnel. We collected data on technologies and users for the last five years and used their additive effect as a proxy for information infrastructure. The data was gathered from ITU and UNCTAD. The operationalized measures are as follows:

1. IIINV: Average level of information infrastructure investment. Time-series analysis data will include subscripts representing the time period. IIINV is represented as a continuous variable in terms of annual per capita information infrastructure investment measured in millions of dollars. This includes the total or lump sum investment associated with acquiring the ownership of information infrastructure components, inclusive of both telecommunications and computing infrastructure. It further includes additions to existing installations where the usage is expected to be over an extended period of time. IIINV is measured in constant U.S. dollars and standardized across countries.

2. IID: Average level of information infrastructure development. This is represented as a continuous variable in terms of the level of IID normalized by the population. Development is exemplified in terms of two distinct categories: technical components and users of the technical components. The technical components considered in IID include the number of land-based telephone and telex networks, satellite and wireless networks, broadband land-based networks, computing hardware, computing software and applications, content management (databases), and human capital (trained support personnel). The other IID component represents the number of users utilizing each of these services (with the exception of the number of support personnel). Because information infrastructure needs vary across country categories, IID components are assigned equal weights, partly because economic growth (e.g., SSG) is a function of both legacy and modern technologies. Information infrastructure demands differ across countries (Baily et al., 1994). For example, there is an increased focus on wireless IID in Southeast Asia for remote access and use. Sub-Saharan Africa, on the other hand, tends to focus much more on developing telephony and satellite-based communications. Because information needs are subsumed by politics, strategy, or topography, countries have ad hoc foci on particular IID components. We assume equal weights for each of the IID components. Furthermore, as it is unequivocally accepted that the strength of an information infrastructure lies not in the technology but in its use, we operationalize IID as a product term through the interaction of IID technical and users of such IID components (with the exception of telecommunications personnel). IID is represented as a normalized index with a numerator sumproduct of information infrastructure components and its users and a denominator of the population.

$$
\mathrm{IID}=\frac{\Sigma X_{i} Y_{i} \text { in Country } i}{\text { Population of Country } i}
$$

where, $X_{i}=i$ th information infrastructure component (in units), $i$ is country group 1,2 , or 3 $\left(n=90 ; n_{i}=30\right)$, and $Y_{i}$ is the number of users for the $i$ th information infrastructure component (in units).

3. $S S G$ : Average level of service-sector contribution toward GDP over time (1996-2000) as a measure of service-sector growth. Time-series analysis data include subscripts representing the time period. The proxy for measuring SSG is measured in terms of annual per capita service-sector contribution toward GDP.

\section{Data Analysis: Rationale and Results}

We augment previous research on IIINVs and SSG by introducing the mediating construct of IID. Our approach toward data analysis is based on developing a systematic framework that sequentially conducts both exploratory and confirmatory statistical analyses. However, before embarking on understanding the causal relationships and 
their directions, we conduct three preliminary tests concerning multicollinearity, spuriousness, and whether differences exist among country categories in terms of IIINV and infrastructure development. Upon completion, we conduct exploratory and confirmatory analyses for gaining additional insights and confirming hypotheses.

\section{Preliminary Tests ${ }^{4}$}

Multicollinearity. We begin by asking a simple question: Do all IIINV add up to the same level of IID? In answering this question, we test for signs of multicollinearity among these variables. We use tolerance level and its reciprocal, variance inflation factor (VIF), to check for multicollinearity. It is generally agreed that a VIF $\geq 2$ is a sign of multicollinearity (Baron \& Kenny, 1986). The use of a conservative statistical power in tests for multicollinearity provides both statistical and discriminant (construct) validity, respectively. Our results do not signify multicollinearity $($ Tolerance $=0.6874 ; \mathrm{VIF}=1.4548)$.

Spuriousness. We proceed to check for spuriousness pertaining to the association of our variables of interest. Pertinent questions may be raised on whether the association between the independent and the dependent variable is actually spurious per se, and largely a product of the presence of the third variable in the model. For example, the association between IIINV and SSG may actually be spurious with the association primarily because of the presence of IID. Similarly, the association between IID and SSG may be attributed to the presence of IIINV, an absence of which may make the association spurious. Results from the partial correlation tests indicate that the relationships between SSG and IID are not spurious and are significantly different from zero $(p<.05)$ when controlled for IIINV and infrastructure development, respectively.

Difference in means. Upon having checked for multicollinearity and spuriousness, we conduct a one-way analysis of variance (ANOVA), using an $F$-test of difference of group means to check whether at least two of the three country categories or tiers are significantly different from each other in each of the areas of IIINV and IID. A significant difference between sample means provides validity for proceeding with further analysis of data, by country categories rather than by aggregating the tiers. The differences are assessed at a 5\% level of significance $(\alpha=.05)$. As a part of testing the ANOVA, we also conducted ShapiroWilks tests for normality and Levene's tests of homogeneity of variance and observed no significant deviations from the assumptions. One-way ANOVA indicates that sample means for all the independent variables, namely, IIINV, and IID, are significantly different across the country tiers.

Stationarity test of the time series. Finally, it is important that the time series used to test the causality between IIINV, IID, and SSG is stationary, that is, that the determination does not change over time and the series has no memory. To identify stationarity, we conducted preliminary diagnostic tests with correlograms. The DickeyFuller (1979) approach for stationarity testing was used as an extension of a $t$-test of an autoregression process by investigating the marginal difference $\Delta X_{t}=\alpha+\partial X_{t-1}+u_{t}$, where $u_{t}$ terms are independent and identically distributed (iid) error terms. The Dickey-Fuller approach forwards a null $\mathrm{H}_{\mathrm{o}}: \partial^{*}=0$ (i.e., nonstationary/unit root) versus the alternative $\mathrm{H}_{\mathrm{a}}: \partial<0$ (i.e., stationary). Our time-series data passed the Dickey-Fuller stationarity test with large negative $t$-statistics $(p<.001)$.

Exploratory and Confirmatory Analyses. With enough evidence to support and justify the distinctive characteristics of our data set, we embark on exploratory analyses for gaining insights and confirmatory analyses for empirically testing our hypotheses.

Exploratory analysis: ANOVA and post hoc tests. We begin our exploratory analysis with an ANOVA followed by post hoc tests that are well suited for tracing differences not limited by the ones specified in theory or our hypothesis. The preliminary ANOVA test rejected the null hypothesis that "the sample means are equal" for both IIINV $\left(F_{(2,87)}=4.281 ; p<0.05\right)$ and $\operatorname{IID}\left(F_{(2,87)}=21.463\right.$; $p<.05)$. For examining whether differences existed at a greater detail, we use Tukey's HSD (honestly significant difference) test for conducting multiple pair wise comparisons between groups to see which groups have different means. Tukey's HSD test reveals whether the group means are significantly different at a specific level of significance. The post hoc tests indicate that mean differences in IIINV between high-income and middle-income or lowincome countries differ significantly $(p<.05)$. However, IIINV levels for middle-income and low-income countries do not differ significantly $(p>.05)$. On the other hand, results show that the mean differences in IID between high-income, middle-income, and low-income countries differ significantly $(p<.05)$. The results indicate disparate IID among middle- and low-income countries, even when their investments are at par. The findings evidence an extremely insightful phenomenon: While the mean differences in the level of IIINV does not differ by middleincome and low-income countries, signifying high levels of investment across the globe, mean differences in the level of IID among the country categories are statistically significant, explicating a convergence of IIINV, but a divergent rift in terms of IID.

Confirmatory analysis for mediation: Regression. We now concentrate on a confirmatory testing of our hypotheses. As we intend to confirm both mediation and recursiveness among the specified constructs, different statistical techniques are employed to achieve our objectives. Our proposed hypotheses integrate the constructs of IIINV, information IID, and SSG. In the process of 
integrating the constructs, we borrow and augment the works of Soh and Markus (1995), Weill (1992), and Dutta (2001) by including the finer dimensions that contribute toward national economic growth. We borrow their efficacious inclusion of temporal lags, while augmenting this research by introducing IID as a mediating imperative ( $\mathrm{Si}$ rimanne, 1996) and supplanting the paradigmatic use of GDP with SSG (Baily et al., 1994).

The proposed mediating relationship of IID is tested using a sequential technique proposed and used by Baron and Kenny (1986) in the presence of a lagged dependent variable. In this technique, two separate regression models are utilized to test the mediation: The first includes the original predictor variable, in this case, IIINV. The second regression model expands on the first by the inclusion of the mediating variable, that is, IID, to the primary predictor, IIINV, with SSG the response variable in both models. The regression models are as follow:

a. Regression model 1 with SSG as the predictor and IIINV as the initial independent variable:

$$
\mathrm{SSG}_{t+1}=a_{1}+b_{1} \mathrm{IIINV}_{t}+\varepsilon_{1}
$$

b. Regression model 2 with the mediating variable IID as the predictor and IIINV as the initial independent variable:

$$
\mathrm{IID}_{t}=a_{2}+b_{2} \mathrm{IIINV}_{t}+\varepsilon_{2}
$$

c. Regression model 3 with SSG as the predictor and IID (mediator) as the independent variable:

$$
\mathrm{SSG}_{t+1}=a_{3}+b_{3} \mathrm{IID}_{t}+\varepsilon_{3}
$$

d. Regression model 4 with SSG as the predictor and IID as the mediating variable and IIINV as the initial variable:

$$
\mathrm{SSG}_{t+1}=a_{4}+b_{4} \mathrm{IIINV}_{t}+b_{5} \mathrm{IID}_{t}+\varepsilon_{4}
$$

We utilize the rules forwarded by Baron and Kenny (1986) to analyze mediation effects:

Beta coefficients $b_{1}, b_{2}, b_{3}, b_{4}$, and $b_{5}$ in regression models $1,2,3$, and 4 must be statistically significant at $\alpha=$ .05 .

The explanatory power $\left(b_{4}\right)$ of IIINV in regression model 4 decreases relative to its initial explanatory power $\left(b_{1}\right)$ in regression model 1 with the inclusion of the mediating variable IID.
Because these rules only provide an informal analysis of the mediating effect of a variable, Baron and Kenny (1986) suggest conducting the Sobel test (Goodman version) that uses a two-tailed $Z$-test of the null hypothesis that the mediator effect is zero in the sample ( $\mathrm{SE}=$ standard error of $\left.b_{i}\right)$.

$$
\begin{aligned}
& Z \text {-Score } \\
& =\frac{b_{2} b_{3}}{\left(b_{2}^{2} \times \mathrm{SE}_{b_{3}^{2}}\right)+\left(b_{3}^{2} \times \mathrm{SE}_{b_{2}^{2}}\right)+\left(\mathrm{SE}_{b_{2}^{2}} \times \mathrm{SE}_{b_{3}^{2}}\right)}
\end{aligned}
$$

Using Baron and Kenny's (1986) rule-based reasoning for examining mediation effects, the results in Table 1 indicate that the weights of the hypothesized independent variables, as shown by their beta coefficients $\left(b_{i}: b_{1}, \ldots, b_{5}\right)$ (where $b_{1}=$ IIINV on SSG, $b_{2}=$ IIINV on IID, $b_{3}=$ IID on SSG, and $b_{4}$ and $b_{5}=$ IIINV and IID on SSG), in regression models $1-4$ are all significant at $\alpha=.05$. Furthermore, upon inclusion of the construct of information infrastructure development (IID), the explanatory power $\left(b_{4}\right)$ of the construct of information infrastructure investments (IIINV) in regression model 4 decreases relative to its initial explanatory power $\left(b_{1}\right)$ in regression model 1 . The relative decrease in the explanatory power of IIINV in the presence of the newly introduced mediating variable of IID provides evidence that the construct of IID is indeed a statistically significant mediator. Furthermore, the Goodman version of the Sobel test, which uses a $Z$-test to check if the effect of the mediator is zero, provides evidence at both the individual country tier and the entire data set that the mediator effect is both considerable and statistically significant (high-income, $Z=12.66, \alpha<.01$; middle-income, $Z=3.98, \alpha<.01$; low-income, $Z=4.77, \alpha<.01$; entire set, $Z=15.1, \alpha<.01)$.

Confirmatory analysis for recursiveness: Bidirectional and bivariate Granger causality. Upon having tested the mediating impact, if any, of IID, we test for any evidence of a significant recursive relationship proposed in hypotheses $\mathrm{H}_{2}$ and $\mathrm{H}_{4}$ using bivariate Granger causality tests. Bivariate Granger causality is incorporated in order to examine whether IIINV and/or IID Granger-causes SSG, and whether SSG, in turn, Granger-causes IID and/or IIINV. In the Granger sense, the causality test involves using $F$ tests to test whether lagged information on the independent variable $Y$ provides any statistically significant information about a variable $X$ in the presence of lagged $X$.

Granger causality involves using time-series data to build an autoregressive model of a single variable, such as SSG. If, upon introduction of the other variable, such as IIINV or IID, the autoregressive model shows significant improvements in prediction statistics, it can be inferred that one variable Granger-causes the other. Using Granger tests, causality is traced by using $F$-tests on the 
TABLE 1

Regression and mediating role of IID

\begin{tabular}{lcccccc}
\hline & Regression 1 & Regression 2 & Regression 3 & Regression 4 & Regression 5 & \\
Country & $Y=$ SSG & $Y=$ IID & $Y=$ SSG & \multicolumn{2}{c}{$Y=$ SSG } & Sobel test \\
\multicolumn{1}{c}{ tiers } & $X_{i}=$ IIINV & $X_{i}=$ IIINV & $X_{i}=$ IID & \multicolumn{2}{c}{$X_{i}=$ IIINV, IID } & (Goodman version), \\
\hline High & $b_{1}$ & $b_{2}$ & $b_{3}$ & $b_{4}$ & $b_{5}$ & $z$ score \\
Middle & $34.953^{* *}$ & $4.877^{*}$ & $175.209^{* *}$ & $4.806^{*}$ & $169.932^{* *}$ & $12.657^{* *}$ \\
Low & $18.95^{*}$ & $3.612^{*}$ & $28.635^{* *}$ & $14.73^{*}$ & $23.676^{* *}$ & $3.975^{* *}$ \\
Total & $25.277^{*}$ & $1.371^{* *}$ & 113.167 & -15.1 & $108.743^{* *}$ & $4.768^{* *}$ \\
\hline
\end{tabular}

${ }^{*}$ Note. Notations for level of significance: ${ }^{*} p<.05,{ }^{* *} p<.01$. Intercept and its significance not considered.

null hypothesis for an unrestricted and restricted equation for an autoregressive lag length using ordinary least squares (OLS). By reversing the variables, one can similarly test for recursive relationships. It is, however, useful to note that Granger tests are sensitive to the choice of lag length.

Although there are multiple ways of conducting Granger causality tests, we follow the specifications provided by the SAS Institute (Roach, 1994), which use a simple approach that begins by assuming an autoregressive lag length of $p$ for specifying an autoregressive unrestricted equation using OLS. The lag is the period of time elapsed between information infrastructure investments and its subsequent returns. Macroeconomic research implicates a lag of approximately 1 year between investment and fruition. The choice of lag length of 1 year is based on implications by the World Bank and the International Development Information Center that it took at least 1 year for information technology transfers to reap benefits. While a specific lag period was not assigned, we used the minimum lag period implicated by existing research (Sirimanne, 1996; Soubbotina \& Sheram, 2000); we thus assume a lag length of 1 year $(p=1)$. In the next step, an $F$ test (or $t$-test, depending on the lag length) is conducted on the null hypothesis that $\beta_{0}=\beta_{1} \ldots \beta_{\mathrm{p}}$, using a restricted OLS equation. The residual sums of squares (RSS) for the restricted $\left(\mathrm{RSS}_{1}\right)$ and unrestricted $\left(\mathrm{RSS}_{0}\right)$ model are then compared. If the test statistic $S_{1}$ is greater than the specified critical value, the null hypothesis can then be rejected and we can conclude that Granger-causality exits among variables. For testing bivariate recursivity, Granger causality can be applied using time-series data in both directions.

The results of the Granger tests are derived using timeseries data for the two hypothesized recursive variables, IID and SSG. The Granger causality test is used to try and reveal the recursive relationship between information infrastructure development (IID) and service-sector growth (SSG) over a lagged time period of $t=1$ year. IID at a specific period (IID ${ }_{t}$ ) Granger-causes increased SSG at a later period $\left(\mathrm{SSG}_{t+1}\right)$. Similarly, it is found that SSG at a particular period $\left(\mathrm{SSG}_{t}\right)$ also Granger-causes IID at a later period (IID IIt $\left._{t}\right)$.

\section{SUMMARY OF RESULTS}

Major results for hypotheses $\mathrm{H}_{1}, \mathrm{H}_{2}$, and $\mathrm{H}_{3}$ are discussed here and tabulated in Table 1:

$\mathrm{H}_{1}$ : Hypothesis 1 was supported by the data. Investments in information infrastructure $\left(\mathrm{IIINV}_{t}\right)$ seem to help generate increased SSG at a later period $\left(\mathrm{SSG}_{t+1}\right.$; lag time 1 year). The finding is consistent for each of the three country categories and also for the total set (high-income, $b_{1}=34.953, \alpha<.05$; middleincome, $b_{1}=18.95, \alpha<.05$; low-income, $b_{1}=$ 25.28, $\alpha<.05$; entire set, $b_{1}=18.012, \alpha<.05$ ). The growth was most pronounced in high-income countries followed by low-income countries and lastly by middle-income countries. While this reinforces the notion that dedicated IIINVs do add to economic growth, exemplified by the rise of the service-sector growth in the economy, it also is suggestive of a disparate growth ratio. An underlying reason could be that middle-income countries are countries in transition, with two parallel areas of development: agrarian and industrial. As a result, the immediate effects of service-sector growth are less pronounced, with most efforts going into developing the information infrastructure. In high-income countries, a preexisting developed information infrastructure creates a multiplier effect for services (Antonelli, 1993; Baily et al., 1994). Interestingly, the pronounced effect of IIINV on SSG in lowincome countries is suggestive of the immediate benefits, even at rudimentary levels such as basic transcription services and small telemedicine centers, of IIINV or service-sector growth. The effect is accentuated given that service sectors in low-income 
countries have commonly remained incognito in the past.

$\mathrm{H}_{2 \mathrm{a}}$ : Hypothesis 2a was also supported. Information infrastructure investments $\left(\mathrm{IIINV}_{t}\right)$ do lead to increased information infrastructure development $\left(\mathrm{IID}_{t}\right)$ in the same time period. The support is reinforced by all the country categories, as well as by the entire data set (high-income, $b_{2}=4.88, \alpha<$ .05 ; middle income, $b_{2}=3.61, \alpha<.05$; lowincome, $b_{2}=1.371, \alpha<.01$; entire set, $b_{2}=$ $2.633, \alpha<.05)$. The results provide support to the fact that IIINV are immediately directed to generate IID, indicating that IID is largely market and demand-centric, needing considerable a priori planning. The results show the different focal areas of different country categories. While high-income and middle-income countries seem to use their IIINV for IID, low-income countries seem to focus more toward increasing immediate returns from the service sector. This could imply disparate dissemination, adoption, and use: something that might negatively affect their economic development in the future. Information infrastructure investments need to be targeted towards ad hoc development and alignment of the technology to country-specific needs to promote further dissemination, adoption, and use.

$\mathrm{H}_{2 \mathrm{~b}}$ : The data provide support for Hypothesis $2 \mathrm{~b}$ with some exceptions. Information infrastructure development $\left(\mathrm{IID}_{t}\right)$ at a particular period is found to positively impact $\mathrm{SSG}$ at a later period $\left(\mathrm{SSG}_{t+1}\right)$. Again, the impact is both considerable and significant for each country tier as well as for the entire data set except for low-income countries (high-income, $b_{3}=$ 175.21, $\alpha<.01$; middle-income, $b_{3}=28.635, \alpha<$ .01 ; low-income: $b_{3}=113.17, \alpha>0.05$; entire set, $\left.b_{3}=104.381, \alpha<.01\right)$. The findings provide evidence that while middle-income and high-income countries can significantly reap economic benefits from a sound IID, low-income countries inherently lack a sound and developed information infrastructure, and thus, fail to show any statistically significant evidence of heightened SSG.

$\mathrm{H}_{3}$ : Hypothesis 3 is also supported. The construct of IID does show significant mediation effects. Results show that information infrastructure development $\left(\mathrm{IID}_{t}\right)$ is a statistically significant mediator between information infrastructure investments $\left(\mathrm{IIINV}_{t}\right)$ and a corresponding increase in SSG at a later period $\left(\mathrm{SSG}_{t+1}\right)$ for each country tier as well as for the entire data set (high-income: $b_{4}=$ $4.81, \alpha<.05 ; b_{5}=169.93, \alpha<.01$; middleincome, $b_{4}=14.73, \alpha<.05 ; b_{5}=23.68, \alpha<$ .01 ; low-income, $b_{4}=-15.1, \alpha>.05, b_{5}=$
108.74, $\alpha<.01 ;$ entire set: $b_{4}=9.291, \alpha<$ $\left..05, b_{5}=82.887, \alpha<.01\right)$. As a minor deviation to the results, the low-income country category results indicate that the influence of infrastructure development as a mediator in the regression equation not only decreased the statistical significance of infrastructure investments upon SSG, but also rendered its influence negative.

$\mathrm{H}_{4 \mathrm{a}}$ : Hypothesis $4 \mathrm{a}$ is partially supported across country tiers. While IIINV seems to Granger-cause IID, a significant recursive relationship does not exist. IIINV does Granger-cause IID at a later period but IID does not Granger-cause IIINV. IIINV $\left(\mathrm{IIINV}_{t}\right)$ Granger-causes IID (IID $t+1$ ) across all countries both positively and significantly (high-income, $F=$ 37.1, $\alpha<.05$; middle-income, $F=26.12, \alpha<$ .05 ; low-income, $F=38.33, \alpha<.05$; entire set, $F=30.25, \alpha<.05)$. Similarly, there seems to be a lack of a statistically significant recursive Grangercausality between IID (IID ${ }_{t}$ ) and IIINV (IIINV $t+1$ ) (high-income, $F=7.21, \alpha>.05$; middle-income, $F=2.11, \alpha>.05$; low-income, $F=4.88, \alpha>$ .05 ; entire set, $F=3.73, \alpha>.05$ ). As with $\mathrm{H}_{2 \mathrm{a}}$, the impact of IIINV seems to have a positive effect on future IID; however, increases in IID across all country tiers do not add to increased IIINV. This finding is suggestive of the fact that infrastructure development does not require quick (i.e., within 1 year) injections of investment. Such a finding should bear well with middle- and low-income countries, which often worry if IIINV capital outflows are too frequent, draining their already strained capital reserves.

$\mathrm{H}_{4 \mathrm{~b}}$ : Hypothesis $4 \mathrm{~b}$ is partly supported. In general, there is a statistically significant Granger-causality-based recursive relationship between information infrastructure development $\left(\mathrm{IID}_{t}\right)$ and $\mathrm{SSG}\left(\mathrm{SSG}_{t+1}\right)$ with the exception of low-income countries (highincome, $F=13.98, \alpha<.05$; middle-income, $F=19.17, \alpha<.05$; low-income, $F=8.19, \alpha>$ .05 ; entire set, $F=14.76, \alpha<.05$ ). Comparatively, there is a similar statistically significant Granger-causality between SSG $\left(\mathrm{SSG}_{t}\right)$ and information infrastructure development (IID ${ }_{t+1}$ ) (highincome: $b_{3}=15.61, \alpha<.05$; median-income, $b_{3}=22.01, \alpha<.01$; low-income, $b_{3}=95.73$, $\alpha<.01$; entire set, $\left.b_{3}=66.03, \alpha<.01\right)$. These results suggest that while infrastructure investments in low-income countries do not seem to lead to servicesector growth, meager service-sector growth does promote future information infrastructure development. One reason for such a finding could be either that low-income countries are less tuned to widespread development or that the lag between IID 
and SSG is higher, especially given their early stages of development.

$\mathrm{H}_{4 \mathrm{c}}$ : Hypothesis $4 \mathrm{c}$ is also supported, with low-income countries as distinct outliers. In general there is a statistically significant Granger-causality-based recursive relationship between information infrastructure development $\left(\mathrm{IIINV}_{t}\right)$ and SSG $\left(\mathrm{SSG}_{t+1}\right)$ with the exception of low-income countries (high-income: $F=22.12, \alpha<.05$; median-income, $F=23.7$, $\alpha<.05$; low-income, $F=13.23, \alpha>.05$; entire set, $F=19.31, \alpha<0.05)$. However, there is a lack of statistically significant relationship indicating that SSG $\left(\mathrm{SSG}_{t}\right)$ does not necessarily Granger-cause information infrastructure investments (IIINV $t+1$ ) (high-income: $b_{3}=15.11$, $\alpha>.05$; middle-income, $b_{3}=14.68, \alpha>.05$; low-income, $b_{3}=35.73, \alpha<.01$; entire set, $\left.b_{3}=18.17, \alpha<.05\right)$. The findings provide evidence that although service-sector growth generally spurs further infrastructure investments (as shown by the significant positive relationship between SSG and future IIINV), low-income countries serve as outliers, most likely because of a weak service sector that is unable to support extended IIINV. Information industries are often a large part of the service sector. Lacking service-sector growth, there is little impetus for further information infrastructure investments. It is a vicious cycle.

\section{DISCUSSION}

The results obtained from the analysis of the data set prompt a number of interesting observations. They are as follows:

1. There is reasonable evidence of a causal relationship between investments in information infrastructure and increased IID and SSG among all country tiers.

2. There is partial support for the recursive relationship between IIINV and IID. While increased information infrastructure investment fosters the development of information infrastructure, infrastructure development does not always spur investments.

3. There is some statistically significant evidence of a causal and recursive relationship between IID and economic development, except for the low-income country tier, where the relationship is statistically insignificant.

4. In most cases, the pattern of directionality between investments, development, and SSG is somewhat different for each country tier, but substantially different for low-income countries. Altogether, there is reasonable evidence of a causal relationship between investments in information infrastructure, and increased IID and SSG among all country tiers.
This empirical study contributes to the existing body of knowledge on global IT in multiple ways. The global investigation of the relationship between IIINV and SSG addresses the questions we had set forth to answer and also allows interesting issues and dimensions to surface. There is a causal relationship between information infrastructure investments and service-sector growth, but it is mediated by infrastructure development. Thus we empirically show that development of, rather than expending on, infrastructure is the key to growth. Additionally, the analysis indicates that the causality is recursive; that is, service-sector growth is likely to prompt further infrastructure investments and development, promoting continuous economic development, for example, the exemplary recursive relationship between the financial sector and development of ATMs. Finally, we find that the causal relationship varies across country categories, with the least developed countries failing to capitalize on their information infrastructure investments because of causes ranging from sociopolitical instability to ineffective public policy leading to disparate infrastructure development and little or no growth. Altogether, there seems to be a positive effect of infrastructure investments and development on servicesector growth, substantiated by growing clusters of service providers, onshore and offshore.

The growth of the service sector is unmistakably evident across the country categories. What is potentially significant is the fact that the transition into the information age is marked by a punctuated shift from production of goods to the production of services. Global entrepreneurs realize that trade in services does not require significant capital outlays, a critical factor in the developing country context, and yet provides opportunities for economic returns. Thereby we have seen increases in service businesses ranging from low-skill services such as back-office transcription services, ticketing, paging services, and so on to high-skill services such as software development, drafting, and database creation.

With lower barriers to entry and the growth of an information-driven service economy, the economic adage of capital outlays as a precursor to economic gains is undergoing a shift. In the United Nations Global Human Development Program Report (United Nations Development Program, 2001), it was pointed out that in the information age economic growth marked by a rapid expansion of an extensive service sector. According to Sirimanne (1996), the "information revolution has transformed the nature and importance of services, making this the largest economic sector and employer" (p. 2). For example, toll-free customer support is provided by Barbados, U.S. judicial opinion databases are developed in Korea, and software management services are provided by India.

The information age has also impacted public sector management in Uganda, where, for the first time in 
TABLE 2

Tukey's HSD (honesty significant different) post hoc multiple comparisons between country tiers

\begin{tabular}{lllccc}
\hline $\begin{array}{c}\text { Dependent } \\
\text { varible }\end{array}$ & (X) TIER_C & (Y) TIER_C & $\begin{array}{c}\text { Mean } \\
\text { difference } \\
(X-Y)\end{array}$ & $\begin{array}{c}\text { Standard } \\
\text { error }\end{array}$ & Significance \\
\hline INFEXP & High-income & Middle-income & $159.8867^{a}$ & 11.15607 & .000 \\
& & Low-income & $175.4805^{a}$ & 11.15607 & .000 \\
& Middle-income & High-income & $-159.8867^{a}$ & 11.15607 & .000 \\
& & Low-income & $15.5938^{a}$ & 11.15607 & .349 \\
& Low-income & High-income & $-175.4805^{a}$ & 11.15607 & .000 \\
& & Middle-income & $-15.5938^{a}$ & 11.15607 & .349 \\
INFDEV & High-income & Middle-income & $97.7243^{a}$ & 5.13291 & .000 \\
& & Low-income & $120.0214^{a}$ & 5.13291 & .000 \\
& Middle-income & High-income & $-97.7243^{a}$ & 5.13291 & .000 \\
& & Low-income & $22.2971^{a}$ & 5.13291 & .000 \\
& Low-income & High-income & $-120.0214^{a}$ & 5.13291 & .000 \\
& & Middle-income & $-22.2971^{a}$ & 5.13291 & .000 \\
\hline
\end{tabular}

The mean difference is significant at the .05 level.

17 years, a financial information system helped integrate and balance the financial statements (Talero, 1997). From providing information on agriculture to promoting education beyond borders, newer and more innovative frontiers have opened up in the information age, creating opportunities for greater economic development.

Another interesting finding comes from the post hoc Tukey HSD test (Table 2). By conducting a pairwise caseby-case comparison, we found that the mean investment in information infrastructure does not significantly differ between middle-income and low-income countries. This could explain the investment interest in IT, possibly in order to reap future benefits or because of an induced effect of investing in IT (Beltz, 1997). While this is quite a natural phenomenon, what makes the results stand out is the fact that although the mean investments between the middle-income and low-income country tiers do not noticeably differ, the mean IID between the same two tiers is considerably different. The finding reveals a crucial fact: how much is invested does not always have a direct bearing on how well it is being invested. The results reinforce our claims by pointing out the lack of difference in IIINV across low-income and middle-income countries while revealing significant differences in their IID. Such a disparity between IIINV and IID is thus a potential problem in developing economies that fail to understand that information infrastructure investment does not ensure information infrastructure development. This again echoes the importance and distinctiveness of IID as the intervening and mediating variable, which is not always reflective of the level or scale of investment (Soubbotina \& Sheram, 2000). The fact that investments are not always a strong predictor for growth, per se, is revealed by the change in the directionality of infrastructure investments on SSG for low-income countries, when in the presence of the mediating variable. There is some statistically significant evidence of a causal and recursive relationship between IID and economic development, except for low-income countries where the relationship is statistically insignificant. Such a finding suggests that while middle-income countries are promoting service-sector growth, low-income countries are lagging behind in building service-sector institutions.

Results of hypotheses $\mathrm{H}_{1}, \mathrm{H}_{2 \mathrm{a}}, \mathrm{H}_{2 \mathrm{~b}}$, and $\mathrm{H}_{3}$ confirming the mediating relationship of IID are displayed in Table 1. Table 1 represents four separate regression models. Regression 1 provides results for hypotheses $\mathrm{H}_{1}$; regression 2 for $\mathrm{H}_{2 \mathrm{a}}$; regression 3 for $\mathrm{H}_{2 \mathrm{~b}}$; and regression 4 for $\mathrm{H}_{3}$, all presented for individual country tiers, and also for the total set of countries.

Results from the OLS regression models (Table 1) and Granger tests using time-series data reveal that while both high-income and middle-income countries reap potential economic rewards, in terms of service-sector growth stemming from IID, low-income countries have failed to reap any such rewards. There exists a low degree of awareness of and access to technology, as well as very low levels of education in low-income countries (Light, 1999). This poses a hindrance to the adoption of vital information infrastructures relevant for the growth of the service sector. Furthermore, many of the service-sector activities in lowincome countries are government controlled, allowing for very low competition (Maddy, 2000) and hence overall poor quality of services, with very little emphasis on the adoption of information infrastructures. However, what 
is noteworthy is that even the meager degree of servicesector development for low-income countries does significantly and positively impact IID. Because service-sector firms concentrate on the use of the information infrastructure, any growth in the service sector brings about greater demand in terms of increasing the user base. This provides a more prudent incorporation and use of information technologies from a given investment, be it via innovation or efficient allocation, resulting in the development of a usable and accessible information infrastructure portfolio. For example, the growth in cybercafes in Africa has prompted a greater user base and demand for an information infrastructure more tuned toward Internet connectivity. This has resulted in a greater impetus on developing an information infrastructure that supports broadband connectivity, rather than past trends that were totally concentrated on laying and upgrading landlines for telephones. In most cases, the pattern of directionality between investments, development, and SSG is somewhat different for each country tier, but substantially different for low-income countries.

At this point, it is necessary to comment on the interesting results in the context of less developed countries (LDCs). LDCs have been flagged by the World Bank as low-income countries suffering from long-term constraints against growth. In particular, these growth constraints include low levels of human resource development and severe structural weaknesses: economic, social, and political (Austin, 1990). The structural weaknesses include very poorly developed and maintained information infrastructures in terms of telecommunications-related infrastructures. Low-income countries are therefore falling behind other countries in the race to construct modern telecommunications networks. This is not because these countries are not installing the latest equipment. In many cases the low-income countries expend heavily on modern and state-of-the-art information infrastructure. Yet there is discriminating evidence in IID vis-à-vis middleand high-income countries. This implies that there are underlying factors behind the countries being at par in terms of investment but lagging behind in development. For example, in many low-income countries, the maintenance of existing equipment leaves much to be desired (Mbarika et al., 2001). In most low-income countries, malfunctioning telephone equipment waits for months before a maintenance team arrives to the rescue. The maintenance process is slow even after problems are identified, unless the team gets "benefits" (a spiced term used for "bribery").

Lack of management plans for maintenance and low salaries open the way to corruption and perpetuate the sluggish maintenance processes. In a study of SubSaharan nations, Odedra et al. (1993) point out that although Africa has spent considerable sums on acquiring information infrastructure, underutilization is rampant. Factors contributing to underutilization range from inadequate infrastructure support prerequisites such as reliable power supply to woefully low computer literacy and unplanned and misdirected investments.

Even worse, among many low-income countries, it is common practice to replace, rather than repair, malfunctioning telecommunications equipment-largely because of an acute lack of technical personnel (Mbarika et al., 2002). Just replacing old equipment with new ones without proper care of already existing equipment does not make the situation better. It inflates investment figures without adding any significant improvements in information infrastructures - once again promoting a vicious cycle. Our data obviate the affliction shared by the lowincome economies.

We understand that there are sociopolitical, cultural, and governance-related factors that moderate our postulates. For example, in India itself, disparate sociopolitical governance has created geographic clusters for information technology development. Hyderabad, a city in southern India, has been able to develop its information infrastructure by bringing together IT investments, technology professionals, and technology users via state government initiatives and planning. The state government granted land to set up technology parks and provided incentives for the development of IT-related businesses. Today Hyderabad hosts multinational companies such as Microsoft, Accenture, Dell, and Computer Associates and also serves as an incubator for local entrepreneurs. In stark contrast, technological development across vast stretches of India remains lackluster. The key to growth, therefore, does not merely rest on IIINV, but requires a deliberate sociopolitical effort toward the development and utilization of the existing information infrastructure.

While the scope of this model does not incorporate such moderators, it opens wide avenues for future studies that could add to the richness and granularity of the proposed relationships. Similarly, while we have built this study upon the premise that IID components are equally weighed in their operationalization, this may not always be the case. Components included in the IID portfolio may share unequal weights based on the importance of specific IID components. Moreover, the weights might be in a constant flux through time and also country tiers. For example, in the period when Western Europe concentrated on developing broadband access, Sub-Saharan Africa was prioritizing (or assigning greater weight to) increasing teledensity. Understanding the essence behind such a disparity and its impact on the proposed model is likely to add interesting insights. Furthermore, this model calls for more idiographic studies that would add validity, consistency, and additional insight. Finally, nomothetic efforts may be massed to provide a more robust operationalization of the constructs. 


\section{CONCLUSION}

The main limitations of this study also provide opportunities for future research. First, the foremost objective of this study was to come up with a baseline statistical representation common to the interplay between variables. A time-series treatment of Granger causality was thus used. However, given the availability of panel data, panel data causality testing (as in Holtz-Eakin et al., 1990) would be a logical extension of our preliminary work, and could provide stronger and more robust implications. Panel data causality testing can take into account the presence of unobserved heterogeneity and avoid the problem of rejecting null hypotheses due to spurious correlation.

Second, in our operationalization of information infrastructure development (IID), we assigned equal weights to each of the components. For example, there are countries that provide greater weight to wireless communications than to application software. This article did not consider weights to the IID components because of their volatility across the countries. However, a weighed average IID index offers more credence, especially if patterns of perceptions can be traced. One caveat to using weights assigned from high-income countries is a potential for bias and misalignment vis-à-vis middle- and low-income economies.

Finally, while we use a lagged period of 1 year between infrastructure investments, development, and service sector growth, we believe the lag deserves a better scrutiny. Lag periods tend to vary not only by country type but also by the type of information infrastructure that a country is investing in or developing for future service-sector growth. Future studies may find it interesting to investigate the impact of variable lag effects on the posited relationships.

Altogether, this study was an attempt to decipher the relationship between IIINV, IID, and SSG and understand the recursive and mutual relationships they share. Overall, the study found significant evidence of the mediating effect of IID on IIINVs and SSG. It therefore adds to the existing body of knowledge by incorporating the construct of IID as a mediating variable to gain insight into why and how IID adds to the service economy in the dawn of the information age. The results pertaining to the antecedent and mediating construct also provide direction and coherence to governments and regulatory bodies by considering inherent growth time lags and differences, if any, between high-income, middle-income, and low-income economies.

The model provides prescriptive evidence for placing a greater emphasis on the importance of developing rather than expending on an information infrastructure. As Odedra et al. (1993) note, what countries need most is not the acquisition of newer and sophisticated technologies but learning to develop and exploit existing information infrastructure through planned acquisition and utilization. A paradigm shift is in the making — countries with thriving service sectors will distinguish themselves not in terms of information infrastructure acquisition but rather in terms of access, application, and use. The basic understanding that technology development far outweighs its acquisition is a necessary prerequisite. A knowledge of what to do (i.e., development over acquisition) and where to focus (i.e., the service sector) should be helpful to practicing policy makers and researchers in understanding the circumstances surrounding macroeconomic growth sustainable through an information infrastructure.

\section{NOTES}

1. We define an information infrastructure as the interconnected network of communications technologies, computers, databases, and personnel that helps support information needs of users.

2. These include all ongoing capital expenditure related to the acquisition, upgrade, and maintenance of a country's information infrastructure.

3. In general, the research on relationship between IIINVs and economic growth has tended to use measures of economic growth have been at a national level, generally measured by the GDP (Clemons \& Row, 1989). The link between IINV and the growth of the service sector in specific has been neglected.

4. The Durbin-Watson test statistic was used to check for autocorrelation of error terms. While the test statistic was inconclusive, a complementing residual plot did not show any patterns of serial autocorrelation. We also conducted Breusch Pagan and White tests for heteroskedasticity and did not find any deviations from homoskedasticity because of the short data intervals with little volatility.

\section{REFERENCES}

Adedeji, A. 1986. Towards a dynamic African economy. London: Vikas. Antonelli, C. 1993. Investment, productivity growth and key technologies: The case of advanced telecommunications. Manchester School of Economic and Social Studies 61:386-397.

Apostopoulos, T. K., and Pramataris, K. C. 1997. information technology investment evaluation: Investment in telecommunication infrastructure. International Journal of Information Management 17(4):287-296.

Austin, J. E. 1990. Managing in developing countries: Strategic analysis and operating techniques. New York: Free Press.

Baily, M. N., Quinn, J. B., Herbert, G. R., and Willett, D. 1994. Information technology: Increasing productivity in services; Executive commentary. Academy of Management Executive 8(3):2851.

Baron, R. M., and Kenny, D. A. 1986. The moderator-mediator variable distinction in social psychological research: Conceptual, strategic, and statistical considerations. Journal of Personality and Social Psychology 51:1173-1182.

Beltz, C. 1997. Global telecommunications rules: The race with technology. Issues in Science and Technology Online 13(3):63-70.

Brynjolfsson, E. 1993. The productivity paradox of information technology. Communications of the ACM 36(12):67-77. 
Cash, J. I., McFarlan, F. W., and McKenney, J. L. 1988. Corporate information systems management: The issues facing senior executives. Homewood, IL: Irwin.

Center for European Economic Research (ZEW). 2002. Growth of knowledge industries. Geneva, Switzerland: Center for Economic Research.

Chakraborty, C., and Nandi, B. 2003. Privatization, telecommunications and growth in selected Asian countries: An econometric analysis. Communications and Strategies 52(1):31-47.

Chifwepa, Vitalicy. 1998. Connectivity in Africa: Use, benefits and constraints of electronic communication. New York: United Nations.

Clemons, E. K., and Row, M. 1989. Information technology and economic reorganization. In Proceedings of the 10th International Conference on Information Systems, pp. 341-361, Boston, December.

Curtis, D. C. A., and Murthy, K. S. R. 1996. Restructuring and economic growth in OECD countries: 1964-1992. Eastern Economic Journal 25(1):17-30.

Datta, P. 2002. Modular systems perspective on the relationship between IT infrastructure and productivity. In International Conference on Information Systems, pp. 23-36, Barcelona, Spain.

Dewan, S., and Kraemer, K. L. 1998. International dimensions of the productivity paradox. Communications of the ACM 41(8): $56-62$.

Dickey, D. A., and Fuller, W. A. 1979. Distribution of the estimations for autoregressive time series with a unit root. Journal of the American Statistical Association 74:427-431.

Dowling, M., Boulton, W., and Elliot, S. 1994. Strategies for change in the service sector: The global telecommunications industry. California Management Review 36(3):57-88.

Dutta, A. 2001. Telecommunications and economic activity: An analysis of Granger causality. Journal of Management Information Systems 17(3):71-95.

Holtz-Eakin, D., Newey, W., and Rosen, H. 1990. Estimating vector autoregressions with panel data. Econometrica 56:13711395.

King, J., Gurbaxani, V., Kraemer, K., McFarlan, F., Raman, K., and Yap, C. 1994. Institutional factors in information technology innovation. Information Systems Research 5(2):139-169.

Lamberton, D. M. 1996. Infrastructure: A nebulous and overworked construct? International Journal of Technology Management 12(5/6):693-706.

Lee, J. K. 1993. Towards the information superhighway. Telecommunications Policy 17(8):631-635.

Light, D. A. 1999. Pioneering distance education in Africa. Harvard Business Review November: 26.

Longwell, J. 2001. Building a convergence business. Jericho, NY: CRN.

Madden, G. and Savage, S. J. 1998. CEE telecommunications investment and economic growth. Information Economics and Policy 10:173-195.

Maddy, M. 2000. Dream deferred: The story of a high-tech entrepreneur in a low-tech world. Harvard Business Review May-June: 26-35.

Mbarika, V., Byrd, T. A., Raymond, J., and McMullen, P. 2001. Investments in telecommunications infrastructure are not the panacea for least developed countries leapfrogging growth of teledensity. International Journal on Media Management 2(3/4):133-142.
Mbarika, V., Raymond, J., and Byrd, T. A. 2002. Growth of teledensity in least developed countries. Journal of Global Information Management 10(2):14-27.

Mbarika, V., Meso, P. M., and Musa, P. F. 2003. A disconnect in stakeholders' perceptions from emerging realities of teledensity growth in africa's least developed countries. Journal of Global Information Management 12(3):1-20.

McLoughlin, G. J. 2000. The National Information Infrastructure: The federal role. U.S. Department of State. Resources, Science, and Industry Division. Document IB95051.

Mohr, L. B. 1982. Explaining organizational behavior: the limits and possibilities of theory and research. San Francisco, CA: JosseyBass.

Odedra, M., Lawrie, M., Bennett, M., and Goodman, S. 1993. SubSaharan Africa: A technological desert. Communications of the ACM 36(2):25-29.

Roach, S. S. 1991. Services under siege-The restructuring imperative. Harvard Business Review September-October: 8291.

Roach, S. S. 1994. Best case study of all. Forbes August 29.

SAS Institute, Inc. 2001. SAS procedures guide, Version 8, vol. 1 and 2. Cary, NC: SAS Institute, Inc.

Saunders, R. J., Warford, J. J., and Wellenius, B. 1994. Telecommunications and economic development. Baltimore, MD: Johns Hopkins Press.

Sikes, A. C. 1987. Information resources: A nation's stake in telecommunications. Telecommunications Policy11(4):330-333.

Sirimanne, S. 1996. The information technology revolution: What about the developing countries? Gatineau, Quebec, Canada: International Development Information Center (IDIC), Canadian International Developmental Agency.

Soh, C., and Markus, L. 1995. How IT creates business value: a process theory synthesis. In Proceedings of the Sixteenth International Conference on Information Systems, pp. 29-41. Amsterdam, the Netherlands.

Soubbotina, T., and Sheram, K. 2000. Beyond economic growth: Meeting the challenges of global development. Washington, DC: The International Bank for Reconstruction and Development, World Bank Report.

Strassman, P. A. 1997. Computers are yet to make companies more productive. Computerworld. September 15:28-29.

Talero, E. 1997. National information infrastructure in developing economies. In National information infrastructure initiatives: Vision \& policy design, ed. B. Kahin and E. Wilson III, 287-306. Cambridge, MA: MIT Press.

United Nations Development Program. 2001. Human development report. New York: UNDP Reports.

Wang, H. E. 1999. ICT and economic development in Taiwan: Analysis of the evidence. Telecommunications Policy 23(3-4):236-243.

Weill, P. 1992. The relationship between investments in information technology and firm performance: A study of the valvemanufacturing sector. Information Systems Research 3(4):307333.

World Bank. 1991. World Bank telecommunications sector reports. Washington, DC: World Bank. 